\title{
PKA and the Structural Kinome
}

\author{
SUSAN S. TAYLOR ${ }^{1,2}$ \\ ALEXANDR P. KORNEV ${ }^{1}$ \\ 'Department of Pharmacology \\ University of California at San Diego, La Jolla \\ 9500 Gilman Drive, San Diego, CA 92093, USA \\ ${ }^{2}$ Department of Chemistry and Biochemistry \\ University of California at San Diego, La Jolla \\ 9500 Gilman Drive, San Diego, CA 92093, USA.

\section{Correspondence:} \\ Susan Taylor \\ E-mail: staylor@ucsd.edu
}

Received December 20, 2016

Revised December 30, 2016.

Accepted December 30, 2016.

\section{Abstract}

In recognition of the first protein kinase structure that was solved 25 years ago, we review the history of the Structural Kinome. What did we learn prior to that first structure of the PKA catalytic subunit, what have we learned since the structure was solved, and what are our remaining challenges for the future?

Introduction. Although protein phosphorylation was discovered in the 1950's when casein was found to be a covalently modified phosphoprotein (1), it was not until the classic work of Krebs and Fischer with phosphorylase kinase (PhosK) that protein phosphorylation was discovered to be a regulatory mechanism (2). Over the ensuing decades we now appreciate that this is one of the major regulatory mechanisms in biology and that the eukaryotic protein kinases (EPKs) constitute one of the largest families encoded for by the human genome (3). Understanding the structure, function, and regulation of these proteins remains as one of the great challenges of the signaling community, and the importance of this superfamily is underscored by their therapeutic importance as drug targets $(4,5)$. As we think about the enormous complexity of the EPKs, which includes not only large membrane-spanning protein kinases such as the epidermal growth factor receptor (EGFR) (6) and the insulin receptor (InsR) (7, 8), as well as giant scaffold protein such as Titan (9), but also the multi-component signaling complexes such as mTOR $(10,11)$, it is important to recognize and appreciate the highly dynamic nature of the EPKs. They have evolved from the eukaryotic-like kinases (ELKs) $(12,13)$ to be molecular switches that are transiently and dynamically regulated. Their substrates are proteins, not small molecules, and unlike metabolic enzymes such as hexokinase and pyruvate kinase, they have not evolved to be efficient catalysts. In many cases, like MAP kinases (MAPKs), PKCs, and the non-receptor tyrosine kinases, dynamic translocation is a critical feature of their regulation while in other cases such as the EGFR the kinase remains localized to the plasma membrane but can be internalized as an endocytotic vesicle with its accessory machinery creating a transient signaling organelle (14). What is clear from all of these EPKs, however, is that they have not evolved to be efficient catalysts; they have evolved to be dynamic and highly regulated molecular switches.

Birth of the Kinome (1959-1979). Cyclic AMP-dependent protein kinase (PKA) was the second regulatory protein kinase to be discovered nearly a decade after PhosK (15). It was originally found as a contaminant of PhosK, and because phosphorylase kinase was its substrate it was initially called phosphorylase kinase kinase. The concept of kinase cascades was also thus embedded in those first two kinases where one kinase activated another. PhosK is a large multi-subunit kinase $\left(\alpha_{4} \beta_{4} \gamma_{4} \delta_{4}\right)$ that is dedicated exclusively to the phosphorylation of a single Ser near the 
C-terminus of glycogen phosphorylase (16). Unlike PhosK, there are many other targets for PKA in the liver, but the fundamental concept of kinase cascades was revealed by these first two protein kinases. With the purification of the PKA catalytic (C) subunit (15) and the subsequent discovery of the PKA regulatory $(\mathrm{R})$ subunits (17-19), it was quickly renamed cAMP-dependent protein kinase. Cyclic GMP-dependent protein kinase (PKG) was the next protein kinase to be discovered (20), but unlike PKA the cGMP binding domains and the kinase domain were part of the same polypeptide chain. PKC came next (21) and, like PKG, it contained regulatory domains that preceded the kinase domain and also bound to second messengers.

Although in those first two decades following the discovery of PhosK and its regulation by protein phosphorylation and prior to the discovery of $\mathrm{vSrc}$ and $\mathrm{cSrc}$, there were only a handful of protein kinases, all exemplified not only the switch mechanism but also the importance of second messengers, which converged in a variety of ways on the protein kinases. Around the same time that Krebs and Fischer were discovering protein kinases, Sutherland discovered cAMP as a second messenger that was synthesized inside the cell in response to a hormone binding to a receptor on the surface of the cell (22). It took two more decades for G-proteins to be discovered (23-25). Two of the major signaling mechanisms in biology, protein phosphorylation and second messenger signaling through cAMP, then converged in PKA. This theme of activation by a second messenger continued with the discovery of cGMP-dependent protein kinase (PKG) in 1970 (20). Calcium regulation of protein kinases was introduced first by PhosK and glycogen phosphorylase, but it the discovery of PKC by Nishizuka in 1977 and its regulation by diacyl glycerol that introduced the concept of lipid second messengers (26). In PKC three signaling mechanisms converge - protein phosphorylation, calcium signaling (27), and lipid second messenger signaling. Myosin light chain kinase, discovered in 1977 (28), continued that theme of calcium regulation and protein phosphorylation. The concept of second messenger regulation of protein phosphorylation was thus well established prior to the discovery of Src and tyrosine phosphorylation.

Protein kinase discovery and disease. For the first two decades kinase discovery was driven by physiology and pharmacology and was built in large part on the pioneering work of Carl and Gertie Cori (29). How do hormones and neurotransmitters control glycogen and glucose metabolism? Although we did not appreciate this at the time, defects in the regulation of glycogen and glucose metabolism are the fundamental issues that define diabetes. In response to glucagon, for example, PKA reprograms the entire metabolic profile of a cell such as the liver turning off glycolysis and turning on gluconeogenesis. Later the insulin receptor was found to also be a protein kinase (8), and this was followed by Akt (PKB)
(30-32) and AMPK (33). All reinforce the importance of dynamic protein phosphorylation as one of the fundamental challenges for physiology and metabolism and one of the most important questions for diabetes, which has become an epidemic in this country. Diabetes kills more people than cancer and the long-term health problems associated with diabetes drive a major segment of our health care costs today.

The discovery of vSrc and the recognition that it was a protein kinase in 1979 opened an entirely new branch of the yet-to-be-discovered kinome (34). It immediately folded oncogenes and cancer into the kinome and enormously expanded the relevance of protein phosphorylation for regulating biological processes. The discovery and characterization of Src also expanded the substrates to include tyrosine as well as serine and threonine (35). Finally the discovery that vSrc was a kinase and even more importantly the cloning of vSrc allowed us to go from individual gene products to genes and within two decades to the entire genome where we could then begin to map disease mutations.

Defining the active site. To define the protein kinase active site in advance of sequencing and before the structure was solved we return to PKA and classical protein chemistry. It was a relatively small protein kinase that could be purified from tissues in reasonable amounts. Recombinant proteins were still in the future. Affinity chromatography was used initially to define essential residues at the active site. Fluorosulfonyl benozoyl adenosine (FSBA), an ATP analog that was first synthesized as an affinity probe by Coleman $(36,37)$, proved to be an excellent inhibitor of the C-subunit. Zoller showed that ATP protected against covalent modification and that a single lysine was modified $(38,39)$ (Figure 1). When the C-subunit was sequenced two years later, Lys72 was identified as being an essential part of the ATP binding site. Using a hydrophobic carbodiimide, dicyclohexyl carbodiimide (DCCD), Buechler later showed in 1983 that Lys 72 could be easily cross-linked to Asp 184 (40) (Figure 1). He also identified Glu91 as another acidic residue that was close to the ATP binding site (41). Like FSBA, modification of Asp184 and Glu91, was protected in the presence of ATP so all of these residues were predicted to be at the active site near the site of catalysis. Site-directed mutagenesis was evolving in the laboratory of Mike Smith in Vancouver and when Zoller went there as a postdoctoral fellow he collaborated with Pawson to carry out one of the first site directed mutagenesis experiments in an EPK. Because the members of the nonreceptors tyrosine kinases were rapidly cloned and sequenced, it was possible to identify in Fps the lysine that corresponded to Lys 72 in PKA and change it to Ala. This kinase was inactive, thereby proving not only that the lysine was conserved but also establishing independently that it was essential for activity (42). Kamps and Sefton carried out the same experiment with Src (43), and K72 

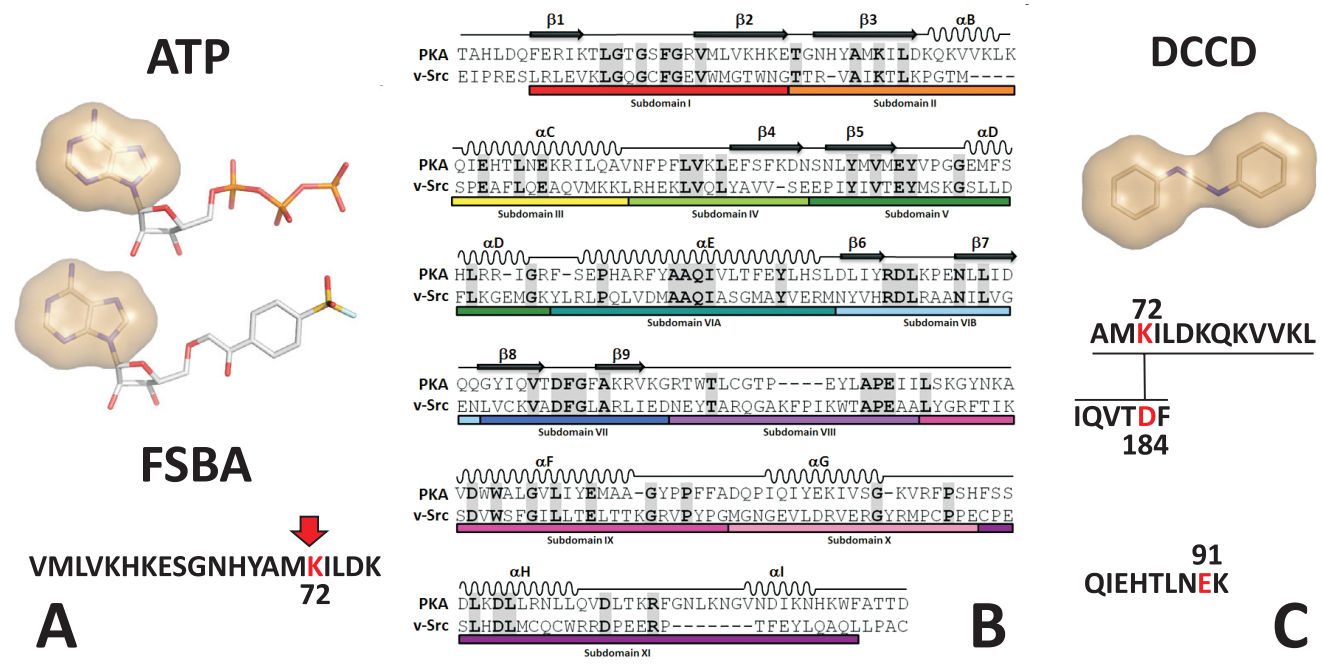

Figure 1. Defining a protein kinase. While initially a protein kinase was identified as a purified protein with biological activity, to chemically classify the protein kinases and to define the active site required classic protein chemistry. A. The ATP binding site was first identified by affinity labeling with fuorosulfonylbenzyl adenosine (FSBA), which labeled a single lysine residue [38, 39]. B. Sequence of the PKA C-subunit aligned with $v$ Src provided the chemical and genetic description of all EPKs [49]. Alignment of multiple EPKs allowed for the identification of conserved subdomains that are color coded [50]. C. The active site was further defined by chemical labeling with a hydrophobic carbo-diimide, dicylohexyl cardoiimide (DCCD), which labeled two carboxylic acid residues, Asp184 and Glu91 and cross-linked Asp184 to Lys72 [40, 41 ].

quickly became the key residue to modify in order to prove that a new kinase was, in fact, a bona fide kinase whose activity was essential for phosphorylation.

Constructing the kinome. While PKA was the second protein kinase to be discovered, in many ways it has been the prototypical kinase that paved the way for understanding the structure and function of all members of the protein kinase superfamily. It was the first to be sequenced (44), and this laid the foundation for constructing the kinome. Although a handful of protein kinases were discovered in the two decades that followed the discovery of PhosK, it was not possible to build the kinome without sequence information. The sequence defined the chemical and genetic blueprint of the EPKs (1981) and also ushered the protein kinases into the world of chemistry. The early sequences of PKA, PKG (45), PhosK (46), and MLCK (47), led by Takio, Walsh and Titani in Seattle, were all done using the laborious classic techniques of protein sequencing that were elucidated in the 1950's by Fred Sanger. The first protein to be sequenced by Sanger and for which he received his first Nobel Prize was, in fact, insulin (48) so once again we can see how basic physiology of glycogen and glucose metabolism drove the early biochemistry and protein chemistry. Once PKA was sequenced, Dayhoff immediately recognized (Figure 1) that the sequence was related to the sequence of the recently cloned vSrc from Rous Sacoma Virus (49), which was reported to have kinase activity (34). This immediately defined the boundaries of the EPKs to include the tyrosine kinases. Cellular Src and Abl were both cloned in 1983, and the advances in cloning technologies then launched an exponential phase in the growth of the EPK superfamily. It also introduced cancer as a major disease target for regulation by protein kinases, and the EPKs have now become a major therapeutic target just beneath G-protein coupled receptors.

In 1988, in the „pre-BLAST” era, using just a handful of EPKs that were mostly sequenced from cloning, Hanks and Hunter aligned the sequences and identified twelve subdomains that still quite accurately reflect the conserved motifs that are scattered throughout the conserved protein kinase core (Figure 1) (50). In today's world of genome sequences, we have thousands of protein kinase sequences aligned and disease mutations are also being revealed at a phenomenal rate (51). In many ways this has provided the foundation for personalized medicine since we can now rapidly determine which particular mutation in which particular kinase drives the cancer in an individual patient. ProKinO where the all of the kinases are aligned on the basis of structure as well as sequence is an especially valuable resource that allows us to query this family in ways that we never even dreamed of in the first three decades when the kinase world was unfolding (52).

Protein Kinase Structure. Twenty five years ago in 1991 the structure of the PKA catalytic subunit was published (Figure 2) (53, 54). It was first protein kinase structure to be solved, and it immediately gave functional context to the conserved sequence motifs. It took us from a one-dimensional sequence-based tree to a three-dimensional template. What did we learn from that first structure (Figure 2)? This structure defined the conserved bi-lobal core that is shared by all EPKs with an N-lobe that was mostly beta structure and a C-lobe 


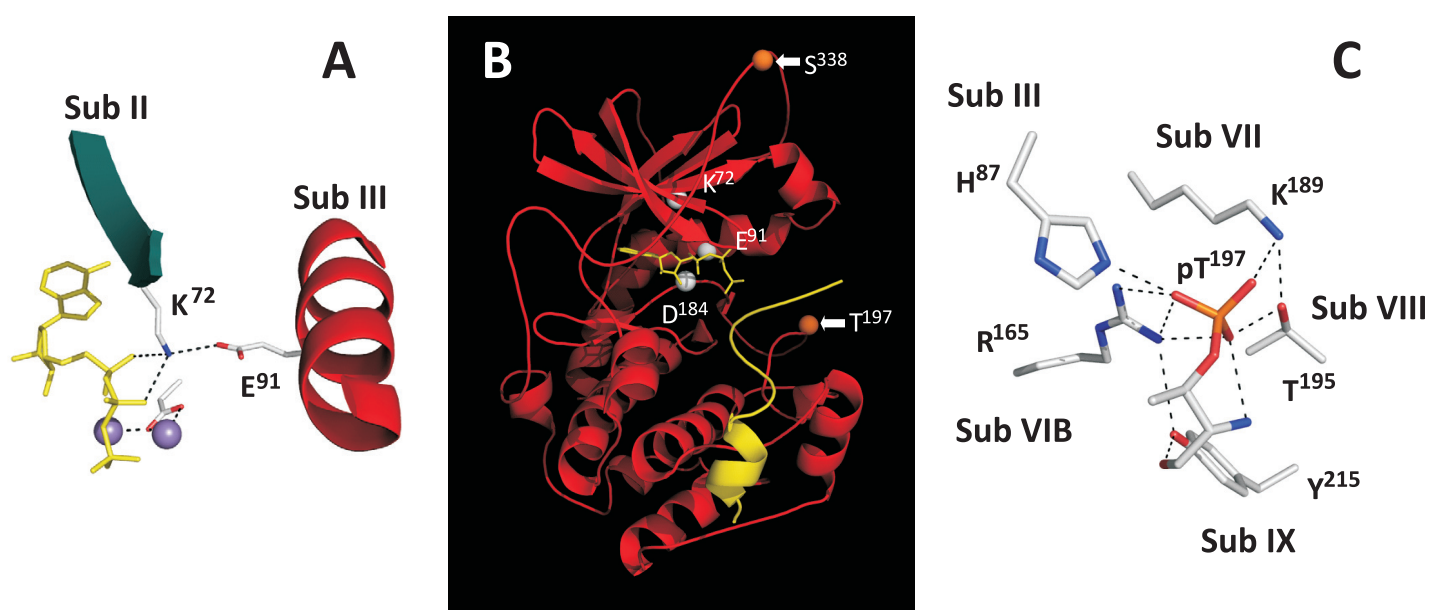

Figure 2. Protein kinase structure. The first protein kinase structure of the PKA C-subunit in 1991 moved the EPKs from a linear sequencedefined family to a three dimensional template. A. The active site of the protein kinase confirmed the affinity labeling and gave functional significance to the subdomains defined by the sequence alignment. B. The structure of the PKA C-subunit described the protein kinase fold [53, 54], and this structure, combined with the subsequent ATP bound structure [56], defined the active site and allowed us to understand the functional roles of the conserved residues (white dots) that mostly clustered around the active site. It also showed how an inhibitor peptide (IP20, yellow) was docked into the active site cleft. Finally it showed how phosphorylation sites (blue dots) contributed to folding and activation. C. Phosphorylation of the Activation Loop on Thr197 contributes to the assembly of the active site. It serves as a nucleation site that integrates multiple subdomains that then reach across the entire molecule.

that was mostly helical. It showed how the conserved motifs mostly cluster around the active site cleft, and it gave structural and functional significance to the subdomains that were originally defined exclusively on the basis of sequence alignments. The motifs based on their primary sequence could now be translated into secondary and tertiary structural elements (Figure 3) (55). The structure also placed K72, D184, and E91 all in close proximity at the edge of the active site cleft and thus completely validated the earlier affinity labeling experiments (Figure 2).

Although it was not emphasized at the time, how the adenine ring of ATP docked into the active site cleft (56)
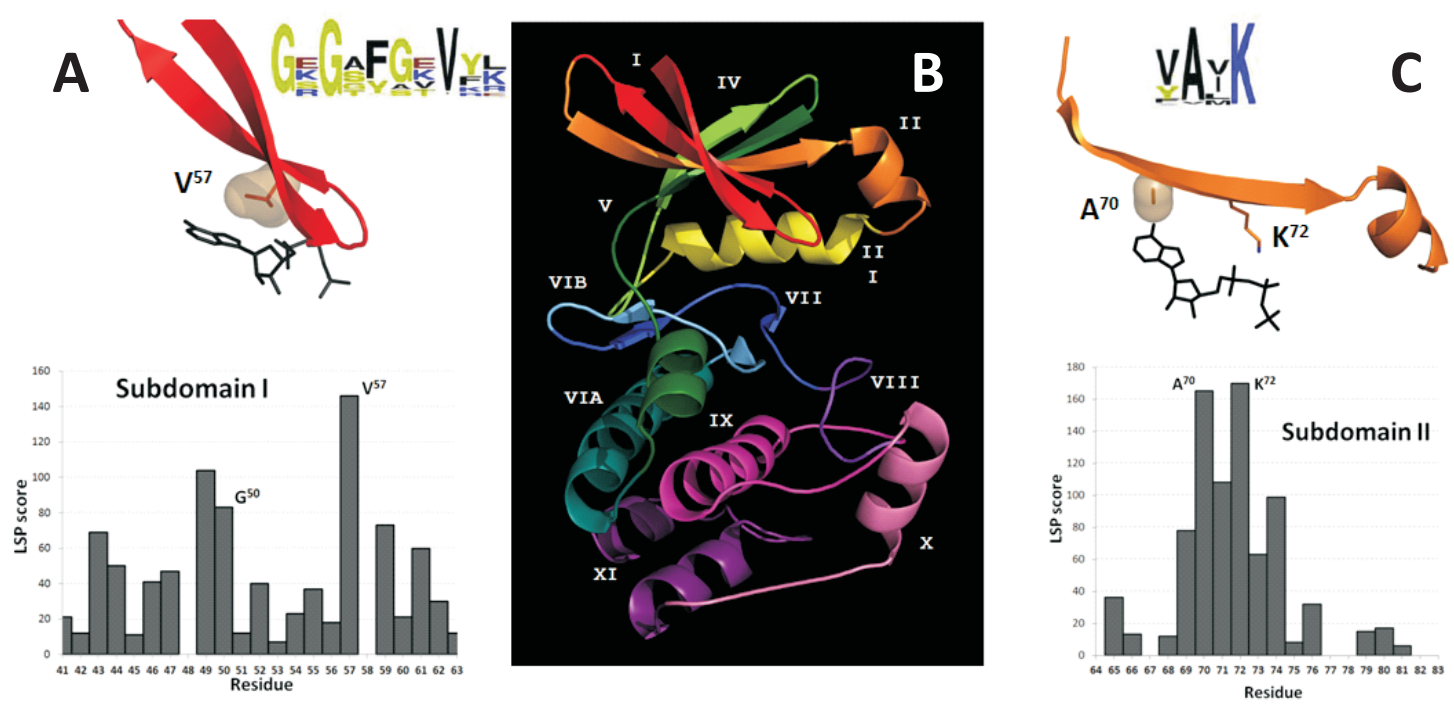

Figure 3. Defining the subdomains. Once the structure was solved, the subdomains were given functional significance. A. Subdomain I serves to cap the adenine ring of ATP, and Val57 is now recognized to be highly conserved as one of the N-lobe capping residues. B. The color-coded subdomains are mapped here onto the tertiary structure of the C-subunit [55]. C. Subdomain II contains the active site lysine, Lys72, as well as the highly conserved Ala70 which is the other N-lobe capping residue for ATP. The LSP alignment graphs for Subdomains I and II are shown at the bottom of panels $A$ and $C$ and the sequence conservation is shown at the top. 
defined an unusual mechanism for ATP binding that contrasted with previous catalytic kinases such as hexokinase. A distinguishing feature of the EPKs is a Glycinerich Loop (G-Loop) that lies between the first two beta strands. This is quite distinct from the P-Loop or Walker Motif that is found in hexokinase and other ATPases, where the g-phosphate of ATP is buried under the P-Loop at the base of the cleft that lies between the two lobes (57). In the EPKs the adenine ring of ATP is buried under the G-Loop at the base of the cleft between the N-Lobe and the $\mathrm{C}$-lobe while the g-phosphate is positioned at the edge of the cleft and is more solvent exposed. It is here where K72 and Glu91 from the N-lobe and Asp184 in the CLobe converge in a highly dynamic way to position the $\gamma$-phosphate of ATP and two metal ions (56). This site defines the essential heart of every EPK although with this first structure we did not appreciate how difficult it would be to trap a kinase in a fully closed conformation nor did we appreciate the full importance of the second metal ion (58). The dynamic G-Loop is a defining feature of the EPKs.

What else did we learn from that first structure? This was a fully active protein kinase that was phosphorylated on its Activation Loop (AL). We also did not appreciate at the time how unusual this was; however, it showed how a single phosphate on the Activation Loop integrated all parts of the molecule. Figure 2 shows how this single phosphate serves as a nucleation site for integrating many of the subdomains. Without this phosphate the C-subunit is very inactive (59) and only recently have we shown that the Activation Loop in the PKA C-subunit, as well as the C-tail, is disordered when the phosphate is missing (60). Although we now have many EPK structures, in most cases the kinase domain is cleaved from the rest of the protein and typically the Activation Loop is partially or fully disordered $(61,62)$. From this first structure of an active PKA C-subunit we did not appreciate the extremely dynamic properties of the Activation Loop. The AL is another feature that distinguishes the EPKs from their evolutionary precursors, the Eukaryotic-like kinases (ELKs). Subsequent comparisons of ELK's and EPKs showed how the highly regulated Activation Loop and the $\alpha \mathrm{G}-\alpha \mathrm{I}$ helical subdomain, linked by the Arg280Glu208 ion pair, are unique to the EPKs and highlight the complexity of regulation that has become the hallmark feature that defines the evolution of the EPKs (12, 13, 63).

The original PKA structure also had a high affinity inhibitor peptide bound to the active site cleft. We also did not appreciate how unusual this was nor did we fully appreciate the nature of intrinsically disordered proteins and peptides that have docking sites and intrinsically disordered regions that only become ordered upon binding to the kinase. PKI is a heat stable protein kinase inhibitor that was discovered by Walsh initially as a contaminant of the catalytic subunit during purification (64). Exten- sive peptide mapping of PKI showed how important the amphipathic helix is for enhancing high affinity binding $(65,66)$. This helix, which is actually stable in solution (67), docks onto the C-lobe and positions the intrinsically disordered region that contains the phosphorylation site precisely at the active site cleft. PKI is a pseudo-substrate, and Walsh also showed how there is synergistic high affinity binding of PKI and ATP (68). In the presence of IP20 the affinity for ATP is $60 \mathrm{nM}$ while the Km for binding in catalysis is $25 \mu \mathrm{M}$. With ATP and IP20 we thus had a structure that in many ways resembled a classic "transition state”. At the time of these first structures we simply did not appreciate how unusual it was to have a substrate docked so perfectly into the active site cleft or to have the second magnesium ion ordered (69). Only later was PKI recognized to be a classic intrinsically disordered protein that has two well-defined helices in solution in contrast to the highly dynamic inhibitor site which only becomes ordered when it binds to the C-subunit (67, 70).

Hydrophobic Spines. What did we not learn from this first structure? What did we miss? While we have learned a great deal about the protein kinase superfamily from PKA, to understand if there were some fundamental rules governing the activation of all protein kinases we needed to compare many kinases. By this time, recognizing the immense importance of the EPKs for disease, there were many protein kinase structures. For this comparison of active and inactive kinases a graph theory method, Local Spatial Pattern (LSP) alignment, was used where the spatial conservation of residues was combined with the conservation of their chemical properties. This comparison of the conserved core of active and inactive kinases revealed the simple but defining concept of a conserved hydrophobic regulatory spine (R-spine) that was dynamically assembled in every active protein kinase (71) (Figure 4).

Although the R-spine is now recognized to be the hallmark signature of every active kinase, it was missed in the original analysis of motifs for several reasons. Our LSP alignment of active and inactive kinases relied on spatial conservation of residues not just on conserved sequence motifs. Although the R-spine residues are always hydrophobic, the sequences are not absolutely conserved (Figure 4). While the precisely fixed interactions that are mediated by electrostatic and hydrogen bonding partners can be captured in the sequence conservation alone, the more fluid positioning of the hydrophobic residues is harder to appreciate and identify. The R-spine is comprised of four hydrophobic residues, two in the C-lobe and two in the N-lobe. It is anchored to the $\alpha \mathrm{F}-\mathrm{Helix}$ by a conserved aspartic acid, Asp220, which was recognized in the original sequence alignment. RS1 (Tyr164 in PKA) is part of the HRD motif that lies at the beginning of the Catalytic Loop. Arg165 reaches to the Activation Loop phosphorylation site in those kinases that have a phosphoryla- 

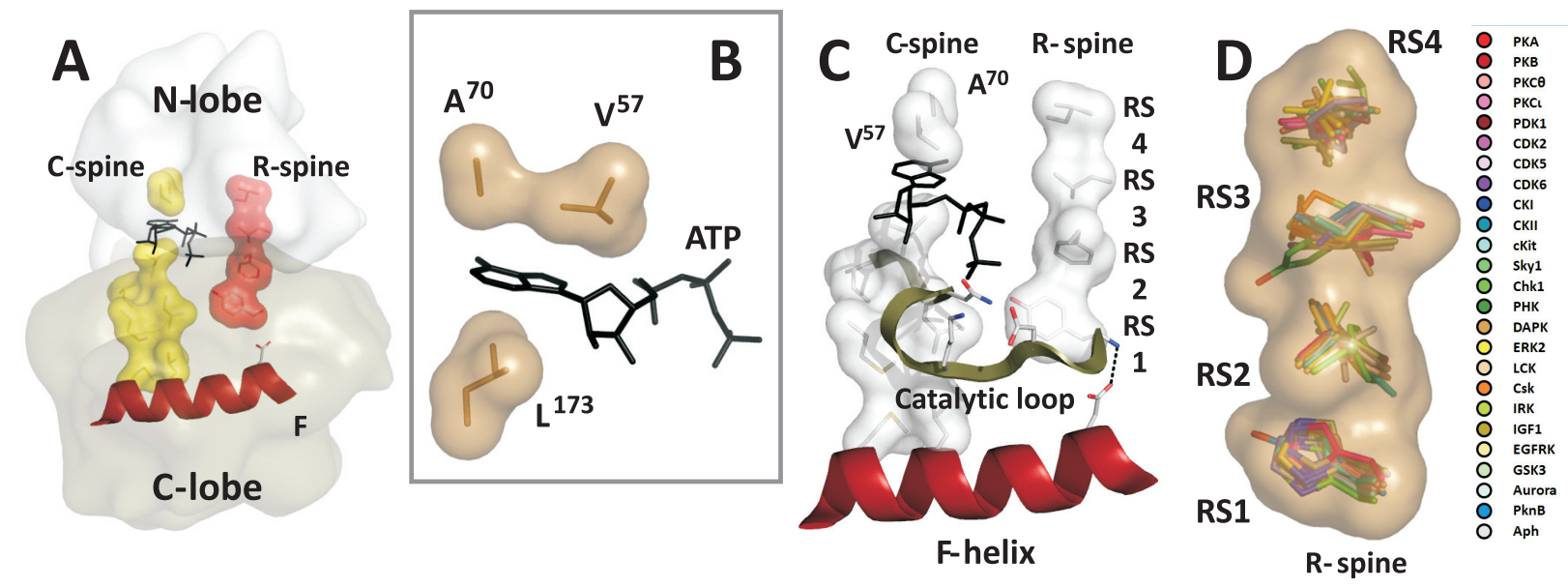

Figure 4. Hydrophobic spines define the underlying architecture of the EPK family. A. The essential elements of the hydrophobic spine architecture include the R-spine and the $C$-spine which are both anchored to the $\alpha F$-Helix [78]. B. The C-spine is completed by the binding of ATP where the adenine ring is capped by Ala70 and Val57 in the N-lobe and Leu173 in the C-lobe. C. The catalytic loop is anchored to both the $C$-spine and the R-spine and the $\alpha F$-Helix. The adenine ring of ATP is anchored to the $C$-Spine while the $\gamma$-phosphate is anchored through the regulatory triad (Lys72, Glu91, and Asp184) to the R-spine. D. The conserved R-spine that is dynamically assembled in every active kinase includes two residues from the C-Lobe (Tyr164 from the HRD motif and Phe185 from the DFG motif) and two residues from the $N$-Lobe (Leu95 from the $\alpha C$ Helix and Leu106 from the $\beta 3$ strand)

tion site in their AL (Figure 2). Asp166 is the catalytic base that positions the P-site hydroxyl moiety in the substrate. RS1 is either a His or a Tyr. RS2 (Phe185) is the DFG motif, and all three residues are highly conserved. Asp184 binds to the second metal ion, and, as indicated above, Asp184 cross-linked to Lys 72 in the early affinity labeling experiments. RS3 and RS4 in the N-lobe are more variable but are often Val or Leu. RS3 is in the $\alpha \mathrm{C}$ helix and lies one turn beyond Asp91, which also interacts with K72. RS 4 begins the $\beta 5$ strand. The $\alpha \mathrm{C}-\beta 4$ loop is a highly conserved motif that was also not appreciated at all in the original structure but is a defining element of every protein kinase. The functional importance of the $\mathrm{R}$-spine and the ways in which mutations can generate a constitutively active kinase were validated in BCR-Abl (72) and BRaf (73-75), which is one of the most commonly mutated kinases in cancer.

Further analysis of the conserved hydrophobic residues revealed a second spine, which is referred to as the catalytic spine or C-Spine (76). The C-spine is assembled by the binding of ATP, in particular by the adenine ring, which is wedged between Ala70 and Val57 in the N-lobe and Leu173 in the $\beta 7$ strand of the C-lobe (Figure 4A). By reaching across the Catalytic Loop the binding of the adenine ring assembles the active site and in particular the three regulatory residues identified by affinity labeling, Lys72, Asp184 and Glu91. Both spines are anchored to the hydrophobic $\alpha$ F-Helix, which spans the C-lobe. It is very unusual to have a hydrophobic helix such as this buried in a globular protein. Most helices in globular proteins are amphipathic. The $\alpha \mathrm{F}-\mathrm{Helix}$ has a conserved Gly in the middle, and it is split into two functional units when the C-subunit is subjected to a Community Map analysis (77). If we look at Val57 and Ala70 in the sequence alignments, they both are as conserved as $\mathrm{K} 72$ and E91, but their functional significance was overlooked until the LSP alignment $(78,79)$ showed that they were also spatially conserved (Figures 3A and 3C).

A closer look at Subdomains I and II reveals some of the key residues that we glossed over in the initial motif analysis. Val57, for example, is in Subdomain I along with the G-loop (Figure 3A), and it precisely defines why the G-loop is different from a P-Loop. Beta strands 1 and 2 sequester the adenine ring of ATP while the P-Loop sequesters the $\gamma$-phosphate. Ala70 lies in Subdomain II in the $\beta 3$ strand two residues before K72. As seen in Figure 3 , the Ala is very highly conserved but its essential functional role was not appreciated until its spatial position relative to the $\mathrm{C}$-spine was considered. The same is true for Val57 (Figure 3C). We simply did not appreciate its conservation and its functional significance in the initial alignment. These two residues, Ala70 and Val57, describe the capping motif in the N-lobe. Leu173 in the C-lobe lies in the $\beta 7$ strand that follows the catalytic loop and provides the C-lobe cap for the adenine ring (Figure 2A).

Opening and closing of the catalytic cleft. Once the active kinase is assembled it must traverse through its catalytic cycle. In the case of PKA, by converting the IP20 peptide from PKI into a substrate (SP20), almost every step of the catalytic cycle has been trapped in a crystal lattice so we have a good static chemical definition of each step $(80,81)$. Kinase activity is typically determined with small peptides such as Kemptide (Leu-Arg-Arg-Ala-SerLeu-Gly) using Michaelis Menten conditions, and under 

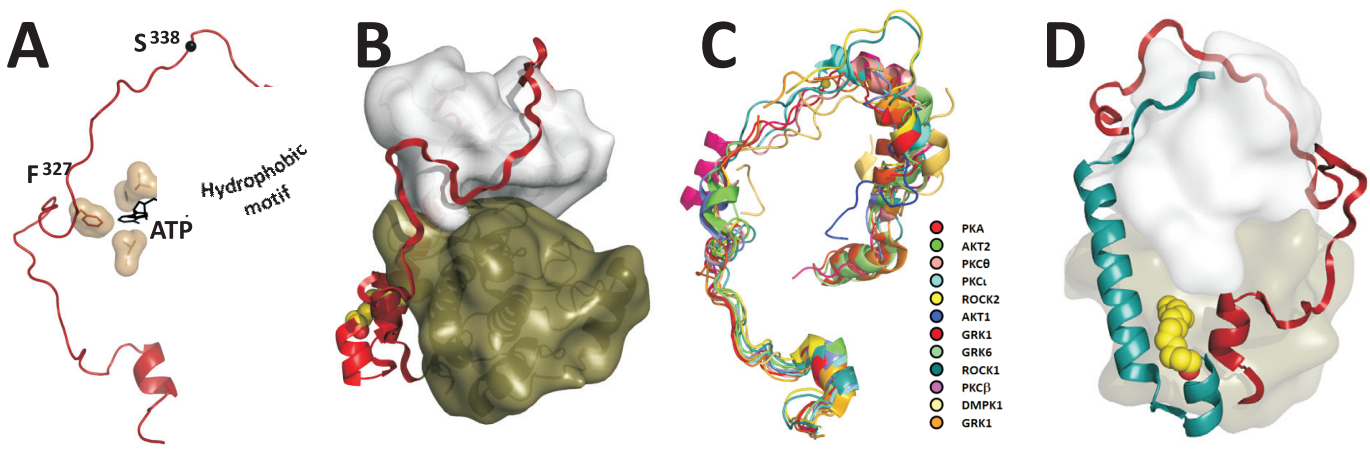

Figure 5. The tails of PKA. The conserved kinase core of the PKA C-subunit is embraced by two tails that each wrap around both lobes of the core. The N-terminal tail (residues 1-39) is myristylated while the C-terminal tail (residues 301-350) is phosphorylated on Ser 338. A. The motifs of the C-tail include Phe327 which is an essential part of the ATP binding site [92, 128], a phosphorylation site at Ser338, and a hydrophobic motif that is anchored to the $\alpha C$-Helix. B. The C-Tail wraps around both lobes of the kinase core ( $N$-lobe in white and $C$-lobe in tan). C. The C-Tail is a conserved feature of all AGC kinases [93]. D. The myristylated N-tail also wraps around both lobes of the core and is dominated by the $\alpha$ A-Helix (yellow balls correspond to the myristyl moiety) [129, 130].

these conditions the phosphorylated peptide is rapidly released leaving release of the metal bound nucleotide as the rate-limiting step (82). For PKA the critical step for release of the nucleotide is the release of the first metal ion that is bound to Asp184 $(81,83)$. In addition, the hinge and twist motions that are associated with opening and closing of the catalytic cleft (84) do not require breaking of either spine.

As discussed above, in contrast to ATPases and metabolic enzymes such as hexokinase, the G-loop in the EPKs traps the adenine ring at the base of the cleft which completes the C-spine and leaves the $\gamma$-phosphate to be transferred at the edge of the cleft. Protein and peptide substrates are then positioned mostly by the C-lobe to accept the phosphate. The motions associated with binding of substrates and transferring the phosphate have not only been trapped with SP20 in crystal structures but also have been carefully described by NMR where one can appreciate both the side chain and backbone dynamics of every residue $(85,86)$. To understand opening and closing of the active site cleft, however, we return to the fully closed conformation where the $\gamma$-phosphate is trapped between the two lobes by the triad that was described by the early affinity labeling. We know, for example, from Ala scanning mutagenesis that both Lys 72 and Glu91 are essential for efficient steady state catalysis (87). However, even though both mutants are deficient in steady state catalysis they can both still bind ATP with affinities that are similar to the wt C-subunit once the Activation Loop is phosphorylated $(88,89)$. In the case of the Glu91Ala mutant, catalytic activity can be rescued by strengthening the Rspine or by removing a key His in the $\alpha \mathrm{C}$-Helix that helps to anchor the $\alpha \mathrm{C}$-Helix in a closed conformation (89) (see Figure $2 \mathrm{C}$ ). These results suggest that the conserved ion pair is more important for synchronizing the opening and closing of the two lobes rather than for simply the binding of ATP. This node (Lys72, Glu91, D184) can thus be thought of as a highly conserved „regulatory triad" that is essential for the regulation of every protein kinase in contrast to the catalytic triad that is conserved in proteases. Three motifs, each containing a spine residue, deliver these residues to the active site cleft. The $\beta 3$ strand containing Lys 72 is the defining conserved motif of Subdomain II and is anchored to the ATP binding site by Ala70. Glu91 lies in the $\alpha \mathrm{C}$ Helix, which is core conserved element of Subdomain III and is positioned by Leu95, an essential R-spine residue in the N-Lobe. Asp184 in the C-lobe is positioned by Phe185 which is another $\mathrm{R}$-spine residue in the DFG motif (Subdomain VII). Embedded within this triad are all the essential features of the EPK superfamily.

Assembly of the active Catalytic Subunit. The PKA C-subunit was also the first protein kinase to be expressed in E. coli (90), and the recombinant protein is fully active and phosphorylated. It contains two stable phosphates, Thr197 on the Activation Loop (AL) and Ser338 on the C-terminal Tail (C-Tail) (Figure 2C). Unlike many protein kinases, perhaps most, these two phosphates in the PKA C-subunit are quite stable. The role of the AL phosphate was discussed earlier; it is a conserved feature of most protein kinases, and, in many cases, assembly of the $\mathrm{R}$-spine is coordinated with AL phosphorylation (60). The C-Tail, however, even though it lies outside the conserved core, is still an essential part of the active kinase. The Nand C-terminal linkers of all protein kinases contribute in very significant ways to activation and regulation. The C-Tail of the C-subunit wraps around both lobes of the conserved core and is essential for ATP binding and catalysis $(91,92)$ (Figure 5). It is actually a highly conserved feature of all AGC kinases (93), and its dynamic regulation by phosphorylation is finely tuned in different ways for each AGC kinase (Figure 5). In the PKA C-subunit the $\mathrm{C}$-tail phosphate is added as part of the maturation process while the $\mathrm{C}$-subunit is still on the ribosome, 
whereas the AL phosphate is likely added post-translationally either by a trans-auto-phosphorylation mechanism that is mediated by another C-subunit or by cisphosphorylation that is mediated by the heterologous kinase, PDK1, which is the major activator of most AGC kinases (94). In contrast, the C-Tail phosphorylation appears to be mediated by a non-canonical cis-auto-phosphorylation mechanism in the process of folding (95). In contrast to most other kinases where these phosphates turnover rapidly, in PKA these phosphates are extremely resistant to removal by phosphatases (95). The important point for PKA is that it is synthesized as a very stable phosphorylated protein and then packaged with cAMP binding regulatory subunits so that its activation is dependent on cAMP, not on the dynamic turnover of the Activation Loop phosphate. To understand PKA signaling in cells it is thus necessary to understand both the R-subunits as well as the full length anchored holoenzymes.

Regulatory subunits. In mammalian cells there are four functionally non-redundant dimeric regulatory $(\mathrm{R})$ subunits (RI $\alpha, \mathrm{RI} \beta$, RII $\alpha$, and $\mathrm{RII} \beta$ ), and PKA specificity is achieved largely by the isoform diversity of the Rsubunits and their targeting to specific sites in the cell by scaffold proteins referred to as A Kinase Anchoring Proteins (AKAPs). Each chain of the R-subunit dimer binds to one $\mathrm{C}$-subunit creating an inactive $\mathrm{R}_{2} \mathrm{C}_{2}$ holoenzyme. All of the R-subunits have a conserved domain organization with a helical dimerization/docking (D/D) domain
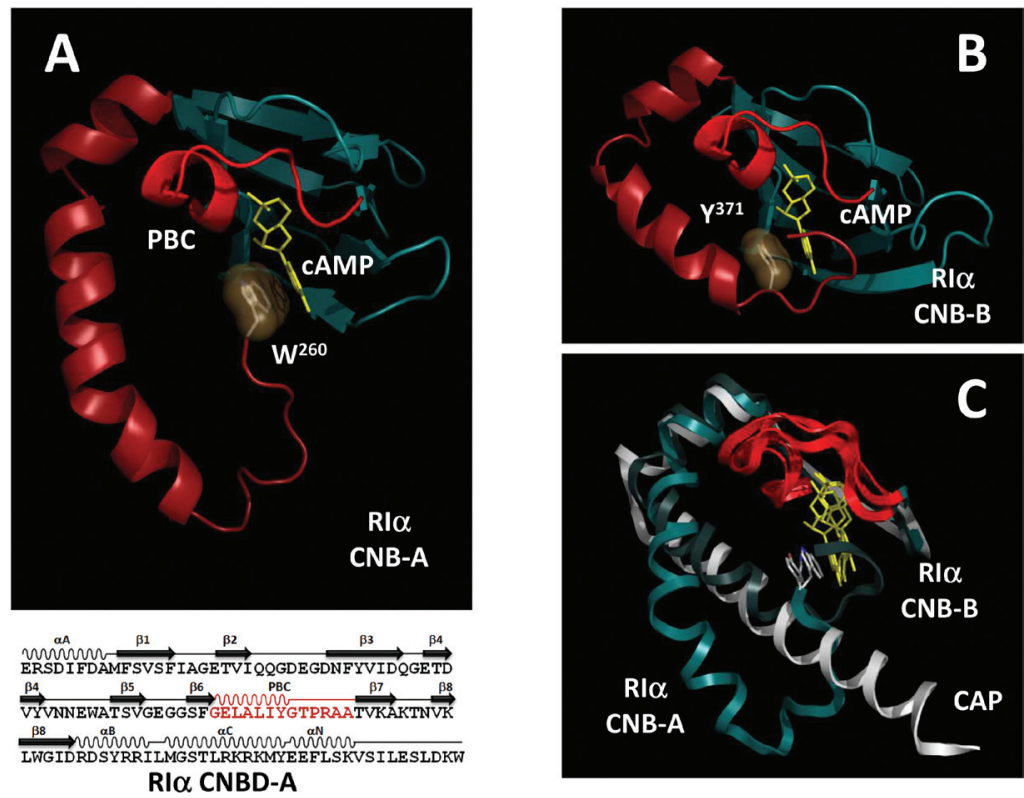

Figure 6. Cyclic nucleotide binding domain. The conserved features of the CNB domain were first defined by aligning the sequences of CAP and the RIa subunit [100]. Capping residues for the adenine ring were identified by affinity labeling. Structures allowed us to define the molecular features of the domain and the detailed features of the cAMP binding site. Affinity labeling of RI $\alpha$ with 8- $N_{3}$-cAMPidentified two sites of modification, Trp260 and Tyr371. A. The capping of cAMP bound to CNB-A is shown as well as a cartoon correlating the $\alpha$ and $\beta$ structural elements with the sequence. The PBC (shown in red) defines the hallmark motif of each $C N B$ domain and contains a conserved arginine that binds to the phosphate moiety of cAMP. B. Cyclic AMP bond to the CNB-B domain is capped by a highly conserved tyrosine, Tyr371 in RIa. C. Overlaid CNB-domains of RI $\alpha$ and CAP. 


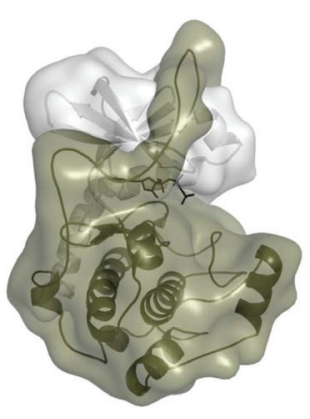

C-subunit

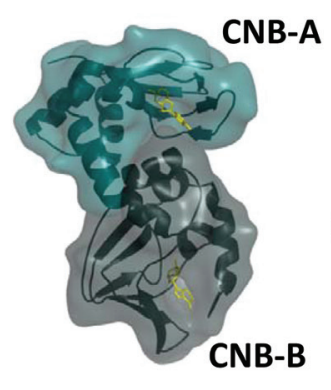

RI $\alpha$ (91-379)

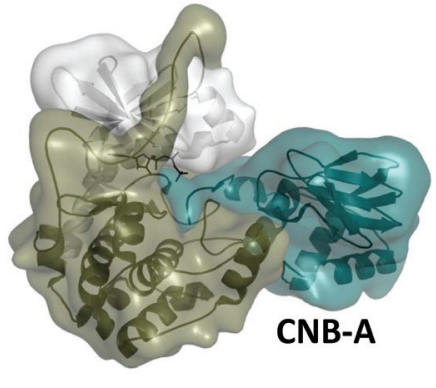

RI $\alpha(91-244): C$

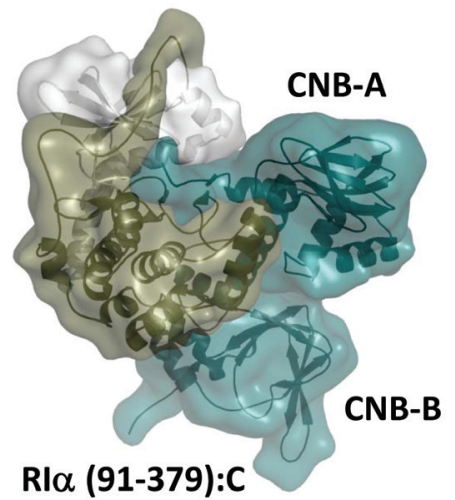

RI $\alpha(91-379): C$

Figure 7. PKA activity is controlled by binding to regulatory subunits. To understand how PKA activity is regulated by cAMP it was necessary to solve structures of complexes between the $R$ - and $C$-subunits. Initial complexes between monomeric forms of RI $\alpha$ showed how the activity of the $C$-subunit was inhibited and how the R-subunit underwent conformational changes as it released cAMP and wrapped around the C-lobe of the C-subunit.

of a monomeric form of RI $\alpha$ (103), while the subsequent structure of cAMP bound to a monomeric form of RII $\beta$ (104) revealed the conserved fold of each domain but a distinct allosteric coupling between the two domains. These structures also showed that the Inhibitor Site, although present, was disordered in the absence of the Csubunit. These structures and their comparison to CAP allowed Berman to build a conserved allosteric framework for cAMP binding (Figure 6C) including the capping residues that were identified by the affinity labeling (105, 106). The conserved signature motif of every CNB domain, however, is a Phosphate Binding Cassette (PBC). The conservation of the $\mathrm{PBC}$, and in particular a conserved arginine, was clear from the sequence conservation and from an early genetic screen for cAMP resistance that was carried out in the 1970's in mouse lymphoma cells $(107,108)$, but its functional significance as the key residue that binds to the phosphate of cAMP was only revealed by the structures. While we learned much about the cAMP binding features of the R-subunits and about their evolution from these crystal structures, they did not explain how the C-subunit was inhibited nor did they explain the highly allosteric activation of the holoenzyme by cAMP. This required structures of $\mathrm{R}: \mathrm{C}$ complexes.

Functional and structural non-redundancy of the holoenzymes. Crystallizing R:C complexes showed how the activity of the catalytic subunit was inhibited by docking of the IS into the active site cleft. This we predicted but did not actually ,see" until the first structure of an $\mathrm{RI} \alpha$ heterodimer was solved with an $\mathrm{RI} \alpha$ that contained a single CNB domain (109). This structure, followed by a structure of a heterodimer of an RI $\alpha$ monomer that contained two CNB domains (110), confirmed that significant conformational changes occur when cAMP is released and the $\mathrm{C}$-subunit is bound. These structures also allowed us to define the allosteric motions of the subdomains in each CNB domain $(105,106)$. However, these $\mathrm{R}: \mathrm{C}$ complexes, as well as subsequent $\mathrm{R}: \mathrm{C}$ complexes with
RII $\alpha$ (111), still did not explain the functional non-redundancy of the R-subunits nor did they explain allosteric activation. For this we needed to solve structures of fulllength holoenzymes.

Only in the $\mathrm{R}_{2} \mathrm{C}_{2}$ holoenzymes can one appreciate the symmetry of PKA and the allosteric features that control activation by cAMP. Our first glimpse of this symmetry came with an RI $\alpha$ :C heterodimer with an extended NLinker that preceded the IS. This crystallized as a dimer of dimers and allowed us to build our first model of an $\mathrm{R}_{2} \mathrm{C}_{2}$ holoenzyme for $\mathrm{RI} \alpha$ that is fully consistent with all of our small angle X-ray and neutron scattering (SAXS/SANS) (112). Structures of the RII $\beta$ holoenzyme (113) and then the RI $\beta$ holoenzyme (114) showed the striking symmetry that is achieved. At the same time these structures also explained how the structural constraints of one heterodimer on the other heterodimer leads to a highly allosteric mechanism for activation. The holoenzyme structure also helps to explain why the Hill Coefficient for activation of the heterodimeric $\mathrm{RII} \beta: \mathrm{C}$ complex is 1.0 in contrast to 1.8 for the $\mathrm{R}_{2} \mathrm{C}_{2} \mathrm{RII} \beta$ holoenzyme (113). Furthermore these three isoform holoenzyme structures (RII $\beta$, RI $\beta$, and the $\mathrm{R} I \alpha$ model) show distinct quaternary structures. This was suggested by early SAXS and SANS studies of the native holoenzymes in solution $(115,116)$, but confirmed in the crystal structures. The holoenzymes are structurally distinct as well as functionally distinct (117).

Targeted PKA Scaffolds create Signalosomes. The specificity of PKA signaling does not end, however, with the structures of the full-length holoenzymes. These holoenzymes are in turn each targeted to specific sites in the cell, usually by AKAPs. In this way the cell creates nodes of PKA signaling that are dedicated to the phosphorylation of specific residues that are typically linked to channel or transporter opening or receptor internalization. The signature motif of every AKAP (Figure 9) is an amphipathic helix that binds with high affinity $(1-40 \mathrm{nM})$ to the 


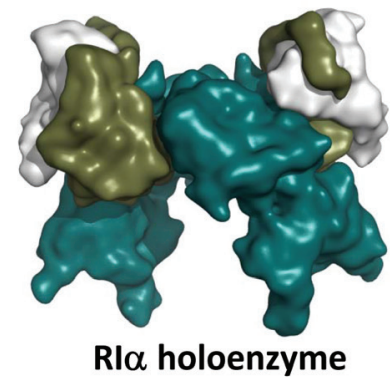

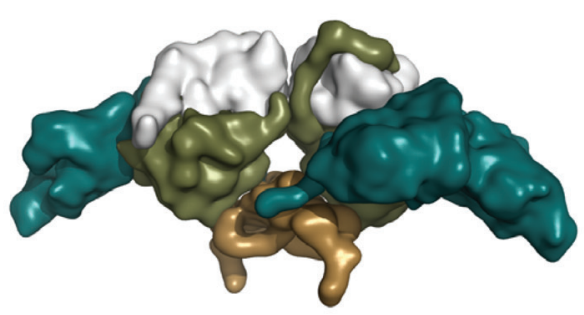

RI $\beta$ holoenzyme

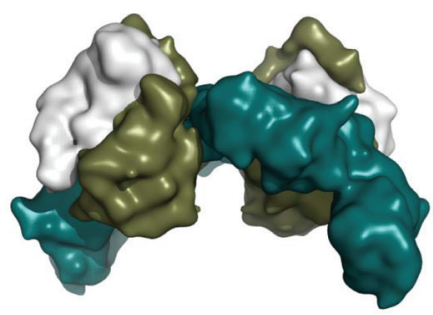

RII $\beta$ holoenzyme

Figure 8. Structural diversity of the PKA holoenzymes. Only with the $R_{2} C_{2}$ holoenzymes can we appreciate the functional and structural diversity of the PKA regulatory subunits. The quaternary structures of each holoenzyme are distinct and help to explain their functional nonredundancy.

N-terminal D/D domain of the R-subunit (118-120). Each AKAP thus recruits PKA, along with other signaling proteins such as phosphatases, phosphodiesterases, and other kinases, to a highly dynamic polyvalent signalosome.

While most AKAPs are specific for RII subunit, some are dual specific and bind to both RI and RII $(121,122)$. Others are highly specific for RI (123) while a few such as GPR161 have absolute specificity for RI-subunits. GPR161, which is the cilia-related G-protein coupled receptor, is also unusual in that the AKAP motif is actually embedded within the C-terminal tail of the receptor (124). DAKAP2 is dual specific AKAP that in the kidney is localized to the proximal kidney tubules and couples through its C-terminal PDZ motif to PDZ-K1, a multiPDZ domain protein that binds to transporters such as the $\mathrm{Na}^{+} / \mathrm{PO}_{3}{ }^{-}$transporter (Figure 9). The way in which the $\mathrm{RI} \alpha \mathrm{D} / \mathrm{D}$ domain couples to the amphipathic helix of DAKAP2 is shown on the Figure 9A while the way in which the AKAP nucleates interactions between three proteins is shown on Figure 9C (120, 125-127).

Remaining Challenges and Opportunities. Our ultimate challenge for PKA signaling is to understand how these dynamic signalosomes toggle between their active and inactive states to regulate processes such as channel or transporter opening. It is a challenge that will require a highly interdisciplinary approach that spans many scales. While crystal structures capture stable static states at high resolution, they do not capture the dynamic features of regulation. NMR can provide essential data on protein and side chain dynamics; however, it will ultimately be essential to observe these processes in live cells. Cryo Electron Microscopy and live cell imaging will be essential to achieve this goal. While we have achieved much over these past 25 years, in many ways we are just beginning to understand the sophisticated and highly

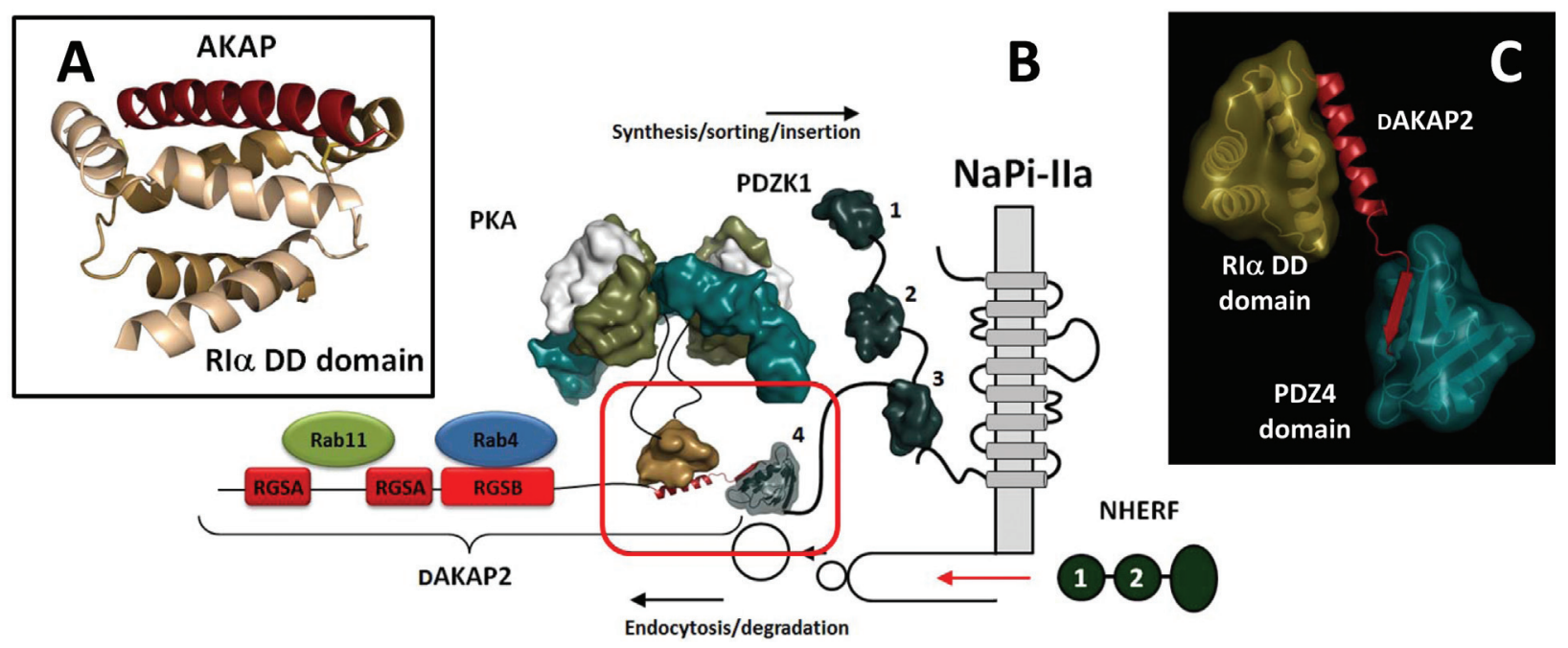

Figure 9. Signalosomes and scaffolds. Each PKA holoenzyme is targeted to specific sites in the cell by scaffold proteins such as the AKAPs. DAKAP2 (or AKAP 11) was identified as a dual specific AKAP that bound to both RI and RII subunits [122]. An amphipathic helix that defines the A Kinase Binding motif $(A K B)$ and is the hallmark signature of every AKAP, this helix binds with high affinity to the helical D/D domain of the R-subunit. A. The AKB of DAKAP2 docked onto the D/D domain of RIa [126]. B. DAKAP2 nucleates a polyvalent complex between PDZ$K 1$ and various transporters and is also bound to Rab4 and Rab11 and contributes to vesicle trafficking [125]. C. Structure of the DAKAP2 AKB bound to both the D/D domain of RII and the PDZ domain of PDZ-K1 shows how the AKAP nucleates a polyvalent complex [127]. 
dynamic mechanisms that mediate regulation by protein phosphorylation. The fundamental importance of this challenge is amplified by the many diseases that are now recognized to be associated with dysfunctional protein kinases. In the case of PKA, for example, disease mutations are associated with both regulatory and catalytic subunits, and the resulting phenotypes are cell and tissue specific. Increasingly these disease phenotypes will help to drive and enhance our understanding of normal PKA signaling.

Acknowledgements: Supported in part by grants of $\mathrm{Na}$ tional Institutes of Health (GM19301, GM34921, and DK54441) as well as funding for many years by the Howard Hughes Medical Institute.

\section{REFERENCES}

1. Burnett, G. and Kennedy, E.P. (1954) The enzymatic phosphorylation of proteins. J Biol Chem. 211, 969-80.

2. Krebs, E.G., Graves, D.J. and Fischer, E.H. (1959) Factors affecting the activity of muscle phosphorylase B kinase. Journal of Biological Chemistry. 234, 2867-2873.

3. Manning, G., Whyte, D.B., Martinez, R., Hunter, T. and Sudarsanam, S. (2002) The protein kinase complement of the human genome. Science. 298, 1912-34. https://doi.org/10.1126/science.1075762

4. Wu, P., Nielsen, T.E. and Clausen, M.H. (2015) FDA-approved small-molecule kinase inhibitors. Trends Pharmacol Sci. 36, 422-39. https://doi.org/10.1016/j.tips.2015.04.005

5. Fabbro, D., Cowan-Jacob, S.W. and Moebitz, H. (2015) Ten things you should know about protein kinases: IUPHAR Review $14 . \mathrm{BrJ}$ Pharmacol. 172, 2675-700. https://doi.org/10.1111/bph.13096

6. Cohen, S., Ushiro, H., Stoscheck, C. and Chinkers, M. (1982) A native 170,000 epidermal growth factor receptor-kinase complex from shed plasma membrane vesicles. J Biol Chem. 257, 1523-31.

7. Kasuga, M., Fujita-Yamaguchi, Y., Blithe, D.L. and Kahn, C.R. (1983) Tyrosine-specific protein kinase activity is associated with the purified insulin receptor. Proc Natl Acad Sci U S A. 80, 2137-41. https://doi.org/10.1073/pnas.80.8.2137

8. Petruzzelli, L., Herrera, R. and Rosen, O.M. (1984) Insulin receptor is an insulin-dependent tyrosine protein kinase: copurification of insulin-binding activity and protein kinase activity to homogeneity from human placenta. Proc Natl Acad Sci U S A. 81, 3327-31. https://doi.org/10.1073/pnas.81.11.3327

9. Mayans, O., van der Ven, P.F., Wilm, M., Mues, A., Young, P., Furst, D.O., Wilmanns, M. and Gautel, M. (1998) Structural basis for activation of the titin kinase domain during myofibrillogenesis. $\mathrm{Na}$ ture. 395, 863-9. https://doi.org/10.1038/27603

10. Brown, E.J., Albers, M.W., Shin, T.B., Ichikawa, K., Keith, C.T., Lane, W.S. and Schreiber, S.L. (1994) A mammalian protein targeted by G1-arresting rapamycin-receptor complex. Nature. 369, 756-8. https://doi.org/10.1038/369756a0

11. Sabatini, D.M., Erdjument-Bromage, H., Lui, M., Tempst, P. and Snyder, S.H. (1994) RAFT1: a mammalian protein that binds to FKBP12 in a rapamycin-dependent fashion and is homologous to yeast TORs. Cell. 78, 35-43. https://doi.org/10.1016/0092-8674(94)90570-3

12. Kannan, N. and Neuwald, A.F. (2005) Did protein kinase regulatory mechanisms evolve through elaboration of a simple structural component? J Mol Biol. 351, 956-72. https://doi.org/10.1016/j.jmb.2005.06.057

13. Taylor, S.S., Keshwani, M.M., Steichen, J.M. and Kornev, A.P. (2012) Evolution of the eukaryotic protein kinases as dynamic molecular switches. Philosophical Transactions of the Royal Society B-Biological Sciences. 367, 2517-2528. https://doi.org/10.1098/rstb.2012.0054

14. Goh, L.K. and Sorkin, A. (2013) Endocytosis of receptor tyrosine kinases. Cold Spring Harb Perspect Biol. 5, a017459.

https://doi.org/10.1101/cshperspect.a017459

15. Walsh, D.A., Perkins, J.P. and Krebs, E.G. (1968) An Adenosine 3',5'-Monophosphate-Dependant Protein Kinase from Rabbit Skeletal Muscle. Journal of Biological Chemistry. 243, 3763-\&.

16. Titani, K., Koide, A., Hermann, J., Ericsson, L.H., Kumar, S., Wade, R.D., Walsh, K.A., Neurath, H. and Fischer, E.H. (1977) Complete amino acid sequence of rabbit muscle glycogen phosphorylase. Proc Natl Acad Sci US A. 74, 4762-6.

https://doi.org/10.1073/pnas.74.11.4762

17. Tao, M., Salas, M.L. and Lipmann, F. (1970) Mechanism of activation by adenosine $3^{\prime}: 5$-cyclic monophosphate of a protein phosphokinase from rabbit reticulocytes. Proc Natl Acad Sci U S A. 67, 408-14. https://doi.org/10.1073/pnas.67.1.408

18. Gill, G.N. and Garren, L.D. (1970) A cyclic-3',5'-adenosine monophosphate dependent protein kinase from the adrenal cortex: comparison with a cyclic AMP binding protein. Biochem Biophys Res Commun. 39, 335-43.

https://doi.org/10.1016/0006-291X(70)90581-4

19. Brostrom, C.O., Corbin, J.D., King, C.A. and Krebs, E.G. (1971) Interaction of the subunits of adenosine 3':5'-cyclic monophosphatedependent protein kinase of muscle. Proc Natl Acad Sci U S A. 68 , 2444-7. https://doi.org/10.1073/pnas.68.10.2444

20. Kuo, J.F. and Greengard, P. (1970) Cyclic nucleotide-dependent protein kinases. VI. Isolation and partial purification of a protein kinase activated by guanosine 3',5'-monophosphate. J Biol Chem. 245, 2493-8.

21. Inoue, M., Kishimoto, A., Takai, Y. and Nishizuka, Y. (1977) Studies on a cyclic nucleotide-independent protein kinase and its proenzyme in mammalian tissues. II. Proenzyme and its activation by calciumdependent protease from rat brain. J Biol Chem. 252, 7610-6.

22. Rall, T.W. and Sutherland, E.W. (1958) Formation of a cyclic adenine ribonucleotide by tissue particles. J Biol Chem. 232, 1065-76.

23. Ross, E.M., Maguire, M.E., Sturgill, T.W., Biltonen, R.L. and Gilman, A.G. (1977) Relationship between the beta-adrenergic receptor and adenylate cyclase. J Biol Chem. 252, 5761-75.

24. Northup, J.K., Sternweis, P.C., Smigel, M.D., Schleifer, L.S., Ross, E.M. and Gilman, A.G. (1980) Purification of the regulatory component of adenylate cyclase. Proc Natl Acad Sci U S A. 77, 6516-20. https://doi.org/10.1073/pnas.77.11.6516

25. Rodbell, M. (1980) The role of hormone receptors and GTP-regulatory proteins in membrane transduction. Nature. 284, 17-22. https://doi.org/10.1038/284017a0

26. Kishimoto, A., Takai, Y., Mori, T., Kikkawa, U. and Nishizuka, Y. (1980) Activation of calcium and phospholipid-dependent protein kinase by diacylglycerol, its possible relation to phosphatidylinositol turnover. J Biol Chem. 255, 2273-6.

27. Takai, Y., Kishimoto, A., Iwasa, Y., Kawahara, Y., Mori, T. and Nishizuka, Y. (1979) Calcium-dependent activation of a multifunctional protein kinase by membrane phospholipids. J Biol Chem. 254, 3692-5.

28. Pires, E.M. and Perry, S.V. (1977) Purification and properties of myosin light-chain kinase from fast skeletal muscle. Biochem J. 167, 137-46. https://doi.org/10.1042/bj1670137

29. Simoni, R.D., Hill, R.L. and Vaughan, M. (2002) Carbohydrate Metabolism: Glycogen Phosphorylase and the Work of Carl F. and Gerty T.Cori. 1928-1943. J Biol Chem. 277, 18e.

30. Jones, P.F., Jakubowicz, T., Pitossi, F.J., Maurer, F. and Hemmings, B.A. (1991) Molecular cloning and identification of a serine/threonine protein kinase of the second-messenger subfamily. Proc Natl Acad Sci US A. 88, 4171-5. https://doi.org/10.1073/pnas.88.10.4171

31. Coffer, P.J. and Woodgett, J.R. (1991) Molecular cloning and characterisation of a novel putative protein-serine kinase related to the cAMP-dependent and protein kinase C families. Eur J Biochem. 201, 475-81. https://doi.org/10.1111/j.1432-1033.1991.tb16305.x 
32. Bellacosa, A., Testa, J.R., Staal, S.P. and Tsichlis, P.N. (1991) A retroviral oncogene, akt, encoding a serine-threonine kinase containing an SH2-like region. Science. 254, 274-7. https://doi.org/10.1126/science.1833819

33. Hardie, D.G. and Carling, D. (1997) The AMP-activated protein kinase--fuel gauge of the mammalian cell? Eur J Biochem. 246, 25973. https://doi.org/10.1111/j.1432-1033.1997.00259.x

34. Erikson, R.L., Collett, M.S., Erikson, E. and Purchio, A.F. (1979) Evidence that the avian sarcoma virus transforming gene product is a cyclic AMP-independent protein kinase. Proc Natl Acad Sci US A. 76, 6260-4. https://doi.org/10.1073/pnas.76.12.6260

35. Hunter, T. and Sefton, B.M. (1980) Transforming gene product of Rous sarcoma virus phosphorylates tyrosine. Proc Natl Acad Sci US A. 77, 1311-5. https://doi.org/10.1073/pnas.77.3.1311

36. Colman, R.F. (1983) Affinity labeling of purine nucleotide sites in proteins. Annu Rev Biochem. 52, 67-91. https://doi.org/10.1146/annurev.bi.52.070183.000435

37. Pal, P.K., Wechter, W.J. and Colman, R.F. (1975) Affinity labeling of the inhibitory DPNH site of bovine liver glutamate dehydrogenase by 5'-fluorosulfonylbenzoyl adenosine. J Biol Chem. 250, 8140-7.

38. Zoller, M.J. and Taylor, S.S. (1979) Affinity labeling of the nucleotide binding site of the catalytic subunit of cAMP-dependent protein kinase using p-fluorosulfonyl-[14C]benzoyl 5'-adenosine. Identification of a modified lysine residue. J Biol Chem. 254, 8363-8.

39. Zoller, M.J., Nelson, N.C. and Taylor, S.S. (1981) Affinity labeling of cAMP-dependent protein kinase with p-fluorosulfonylbenzoyl adenosine. Covalent modification of lysine 71. J Biol Chem. 256, 10837-42.

40. Buechler, J.A. and Taylor, S.S. (1989) Dicyclohexylcarbodiimide cross-links two conserved residues, Asp-184 and Lys-72, at the active site of the catalytic subunit of cAMP-dependent protein kinase. Biochemistry. 28, 2065-70. https://doi.org/10.1021/bi00431a015

41. Buechler, J.A. and Taylor, S.S. (1988) Identification of aspartate-184 as an essential residue in the catalytic subunit of cAMP-dependent protein kinase. Biochemistry. 27, 7356-61. https://doi.org/10.1021/bi00419a027

42. Weinmaster, G., Zoller, M.J. and Pawson, T. (1986) A lysine in the ATP-binding site of P130gag-fps is essential for protein-tyrosine kinase activity. EMBO J. 5, 69-76.

43. Kamps, M.P., Taylor, S.S. and Sefton, B.M. (1984) Direct evidence that oncogenic tyrosine kinases and cyclic AMP-dependent protein kinase have homologous ATP-binding sites. Nature. 310, 589-92. https://doi.org/10.1038/310589a0

44. Shoji, S., Parmelee, D.C., Wade, R.D., Kumar, S., Ericsson, L.H., Walsh, K.A., Neurath, H., Long, G.L., Demaille, J.G., Fischer, E.H. and Titani, K. (1981) Complete amino acid sequence of the catalytic subunit of bovine cardiac muscle cyclic AMP-dependent protein kinase. Proc Natl Acad Sci US A. 78, 848-51. https://doi.org/10.1073/pnas.78.2.848

45. Takio, K., Wade, R.D., Smith, S.B., Krebs, E.G., Walsh, K.A. and Titani, K. (1984) Guanosine cyclic 3',5'-phosphate dependent protein kinase, a chimeric protein homologous with two separate protein families. Biochemistry. 23, 4207-18. https://doi.org/10.1021/bi00313a030

46. Reimann, E.M., Titani, K., Ericsson, L.H., Wade, R.D., Fischer, E.H. and Walsh, K.A. (1984) Homology of the gamma subunit of phosphorylase b kinase with cAMP-dependent protein kinase. Biochemistry. 23, 4185-92. https://doi.org/10.1021/bi00313a027

47. Takio, K., Blumenthal, D.K., Edelman, A.M., Walsh, K.A., Krebs, E.G. and Titani, K. (1985) Amino acid sequence of an active fragment of rabbit skeletal muscle myosin light chain kinase. Biochemistry. 24, 6028-37. https://doi.org/10.1021/bi00343a002

48. Sanger, F. (1945) The free amino groups of insulin. Biochem J. 39, 507-15. https://doi.org/10.1042/bj0390507

49. Barker, W.C. and Dayhoff, M.O. (1982) Viral src gene products are related to the catalytic chain of mammalian cAMP-dependent protein kinase. Proc Natl Acad Sci US A. 79, 2836-2839.

https://doi.org/10.1073/pnas.79.9.2836
50. Hanks, S.K., Quinn, A.M. and Hunter, T. (1988) The protein kinase family: conserved features and deduced phylogeny of the catalytic domains. Science. 241, 42-52.

https://doi.org/10.1126/science.3291115

51. Richardson, C.J., Gao, Q., Mitsopoulous, C., Zvelebil, M., Pearl, L.H. and Pearl, F.M. (2009) MoKCa database--mutations of kinases in cancer. Nucleic Acids Res. 37, D824-31.

https://doi.org/10.1093/nar/gkn832

52. McSkimming, D.I., Dastgheib, S., Talevich, E., Narayanan, A., Katiyar, S., Taylor, S.S., Kochut, K. and Kannan, N. (2015) ProKinO: A Unified Resource for Mining the Cancer Kinome. Hum Mutat. 36, 175-86. https://doi.org/10.1002/humu. 22726

53. Knighton, D.R., Zheng, J.H., Ten Eyck, L.F., Ashford, V.A., Xuong, N.H., Taylor, S.S. and Sowadski, J.M. (1991) Crystal structure of the catalytic subunit of cyclic adenosine monophosphate-dependent protein kinase. Science. 253, 407-14.

https://doi.org/10.1126/science.1862342

54. Knighton, D.R., Zheng, J.H., Ten Eyck, L.F., Xuong, N.H., Taylor, S.S. and Sowadski, J.M. (1991) Structure of a peptide inhibitor bound to the catalytic subunit of cyclic adenosine monophosphate-dependent protein kinase. Science. 253, 414-20. https://doi.org/10.1126/science.1862343

55. Niedner, R.H., Buzko, O.V., Haste, N.M., Taylor, A., Gribskov, M. and Taylor, S.S. (2006) Protein kinase resource: an integrated environment for phosphorylation research. Proteins. 63, 78-86. https://doi.org/10.1002/prot.20825

56. Zheng, J., Knighton, D.R., ten Eyck, L.F., Karlsson, R., Xuong, N., Taylor, S.S. and Sowadski, J.M. (1993) Crystal structure of the catalytic subunit of cAMP-dependent protein kinase complexed with MgATP and peptide inhibitor. Biochemistry. 32, 2154-61. https://doi.org/10.1021/bi00060a005

57. Ramakrishnan, C., Dani, V.S. and Ramasarma, T. (2002) A conformational analysis of Walker motif A [GXXXXGKT (S)] in nucleotide-binding and other proteins. Protein Eng. 15, 783-98. https://doi.org/10.1093/protein/15.10.783

58. Bao, Z.Q., Jacobsen, D.M. and Young, M.A. (2011) Briefly bound to activate: transient binding of a second catalytic magnesium activates the structure and dynamics of CDK2 kinase for catalysis. Structure. 19, 675-90. https://doi.org/10.1016/j.str.2011.02.016

59. Steichen, J.M., Iyer, G.H., Li, S., Saldanha, S.A., Deal, M.S., Woods, V.L., Jr. and Taylor, S.S. (2010) Global consequences of activation loop phosphorylation on protein kinase A.J Biol Chem. 285, 3825 32. https://doi.org/10.1074/jbc.M109.061820

60. Steichen, J.M., Kuchinskas, M., Keshwani, M.M., Yang, J., Adams, J.A. and Taylor, S.S. (2012) Structural basis for the regulation of protein kinase A by activation loop phosphorylation. J Biol Chem. 287, 14672-80. https://doi.org/10.1074/jbc.M111.335091

61. Johnson, L.N., Noble, M.E. and Owen, D.J. (1996) Active and inactive protein kinases: structural basis for regulation. Cell. 85, 149-58. https://doi.org/10.1016/S0092-8674(00)81092-2

62. Nolen, B., Taylor, S. and Ghosh, G. (2004) Regulation of protein kinases; controlling activity through activation segment conformation. Mol Cell. 15, 661-75.

https://doi.org/10.1016/j.molcel.2004.08.024

63. Yang, J., Wu, J., Steichen, J.M., Kornev, A.P., Deal, M.S., Li, S., Sankaran, B., Woods, V.L., Jr. and Taylor, S.S. (2012) A conserved glu-arg salt bridge connects coevolved motifs that define the eukaryotic protein kinase fold. J Mol Biol. 415, 666-79.

https://doi.org/10.1016/j.jmb.2011.11.035

64. Walsh, D.A., Ashby, C.D., Gonzalez, C., Calkins, D., Fischer, E.H. and Kreb, E.G. (1971) Purification and characterization of a protein inhibitor of adenosine 3',5'-monophosphate-dependent protein kinases. J Biol Chem. 246, 1977-85.

65. Scott, J.D., Glaccum, M.B., Fischer, E.H. and Krebs, E.G. (1986) Primary-structure requirements for inhibition by the heat-stable inhibitor of the cAMP-dependent protein kinase. Proc Natl Acad Sci U S A. 83, 1613-6. https://doi.org/10.1073/pnas.83.6.1613 
66. Walsh, D.A., Angelos, K.L., Van Patten, S.M., Glass, D.B. and Garetto, L.P. (1990) The Inhibitor Protein of the cAMP-Dependent Protein Kinase. In Peptides and Protein Phosphorylation (B. E. Kemp, ed) CRC Press, Inc., Boca Raton 43-84.

67. Hauer, J.A., Barthe, P., Taylor, S.S., Parello, J. and Padilla, A. (1999) Two well-defined motifs in the cAMP-dependent protein kinase inhibitor (PKIalpha) correlate with inhibitory and nuclear export function. Protein Sci. 8, 545-53. https://doi.org/10.1110/ps.8.3.545

68. Whitehouse, S. and Walsh, D.A. (1983) Mg X ATP2-dependent interaction of the inhibitor protein of the cAMP-dependent protein kinase with the catalytic subunit. J Biol Chem. 258, 3682-92.

69. Herberg, F.W., Doyle, M.L., Cox, S. and Taylor, S.S. (1999) Dissection of the nucleotide and metal-phosphate binding sites in CAMPdependent protein kinase. Biochemistry. 38, 6352-60. https://doi.org/10.1021/bi982672w

70. Hauer, J.A., Taylor, S.S. and Johnson, D.A. (1999) Binding-dependent disorder-order transition in PKI alpha: a fluorescence anisotropy study. Biochemistry. 38, 6774-80. https://doi.org/10.1021/bi983074k

71. Kornev, A.P., Haste, N.M., Taylor, S.S. and Ten Eyck, L.F. (2006) Surface comparison of active and inactive protein kinases identifies a conserved activation mechanism. Proceedings of the National Academy of Sciences of the United States of America. 103, 17783-17788. https://doi.org/10.1073/pnas.0607656103

72. Azam, M., Seeliger, M.A., Gray, N.S., Kuriyan, J. and Daley, G.Q. (2008) Activation of tyrosine kinases by mutation of the gatekeeper threonine. Nat Struct Mol Biol. 15, 1109-18. https://doi.org/10.1038/nsmb.1486

73. Hu, J., Stites, E.C., Yu, H., Germino, E.A., Meharena, H.S., Stork, P.J., Kornev, A.P., Taylor, S.S. and Shaw, A.S. (2013) Allosteric Activation of Functionally Asymmetric RAF Kinase Dimers. Cell. 154, 1036-46. https://doi.org/10.1016/j.cell.2013.07.046

74. Hu, J., Ahuja, L.G., Meharena, H.S., Kannan, N., Kornev, A.P., Taylor, S.S. and Shaw, A.S. (2015) Kinase regulation by hydrophobic spine assembly in cancer. Mol Cell Biol. 35, 264-76. https://doi.org/10.1128/MCB.00943-14

75. Shaw, A.S., Kornev, A.P., Hu, J., Ahuja, L.G. and Taylor, S.S. (2014) Kinases and pseudokinases: lessons from RAF. Mol Cell Biol. 34, 1538-46. https://doi.org/10.1128/MCB.00057-14

76. Kornev, A.P., Taylor, S.S. and Ten Eyck, L.F. (2008) A helix scaffold for the assembly of active protein kinases. Proc Natl Acad Sci US A. 105, 14377-82. https://doi.org/10.1073/pnas.0807988105

77. McClendon, C.L., Kornev, A.P., Gilson, M.K. and Taylor, S.S. (2014) Dynamic architecture of a protein kinase. Proc Natl Acad Sci US A. 111, E4623-31. https://doi.org/10.1073/pnas.1418402111

78. Taylor, S.S. and Kornev, A.P. (2011) Protein kinases: evolution of dynamic regulatory proteins. Trends Biochem Sci. 36, 65-77. https://doi.org/10.1016/j.tibs.2010.09.006

79. Kornev, A.P. and Taylor, S.S. (2015) Dynamics-Driven Allostery in Protein Kinases. Trends Biochem Sci. 40, 628-47. https://doi.org/10.1016/j.tibs.2015.09.002

80. Bastidas, A.C., Deal, M.S., Steichen, J.M., Guo, Y., Wu, J. and Taylor, S.S. (2013) Phosphoryl transfer by protein kinase a is captured in a crystal lattice. J Am Chem Soc. 135, 4788-98. https://doi.org/10.1021/ja312237q

81. Bastidas, A.C., Wu, J. and Taylor, S.S. (2015) Molecular features of product release for the PKA catalytic cycle. Biochemistry. 54, 2-10. https://doi.org/10.1021/bi500684c

82. Lew, J., Taylor, S.S. and Adams, J.A. (1997) Identification of a partially rate-determining step in the catalytic mechanism of cAMPdependent protein kinase: a transient kinetic study using stoppedflow fluorescence spectroscopy. Biochemistry. 36, 6717-24. https://doi.org/10.1021/bi963164u

83. Khavrutskii, I.V., Grant, B., Taylor, S.S. and McCammon, J.A. (2009) A transition path ensemble study reveals a linchpin role for $\mathrm{Mg}(2+)$ during rate-limiting ADP release from protein kinase A. Biochemistry. 48, 11532-45. https://doi.org/10.1021/bi901475g

84. Tsigelny, I., Greenberg, J.P., Cox, S., Nichols, W.L., Taylor, S.S. and Ten Eyck, L.F. (1999) 600 ps molecular dynamics reveals stable sub- structures and flexible hinge points in cAMP dependent protein kinase. Biopolymers. 50, 513-24.

https://doi.org/10.1002/(SICI)1097-0282(19991015)50:5<513::AIDBIP5>3.0.CO;2-I

85. Masterson, L.R., Shi, L., Metcalfe, E., Gao, J., Taylor, S.S. and Veglia, G. (2011) Dynamically committed, uncommitted, and quenched states encoded in protein kinase A revealed by NMR spectroscopy. Proc Natl Acad Sci US A. 108, 6969-74. https://doi.org/10.1073/pnas.1102701108

86. Srivastava, A.K., McDonald, L.R., Cembran, A., Kim, J., Masterson, L.R., McClendon, C.L., Taylor, S.S. and Veglia, G. (2014) Synchronous Opening and Closing Motions Are Essential for cAMP-Dependent Protein Kinase A Signaling. Structure. 22, 1735-43. https://doi.org/10.1016/j.str.2014.09.010

87. Gibbs, C.S. and Zoller, M.J. (1991) Rational scanning mutagenesis of a protein kinase identifies functional regions involved in catalysis and substrate interactions. J Biol Chem. 266, 8923-31.

88. Iyer, G.H., Moore, M.J. and Taylor, S.S. (2005) Consequences of lysine 72 mutation on the phosphorylation and activation state of cAMP-dependent kinase. J Biol Chem. 280, 8800-7. https://doi.org/10.1074/jbc.M407586200

89. Meharena, H.S., Fan, X., Ahuja, L.G., Keshwani, M.M., McClendon, C.L., Chen, A.M., Adams, J.A. and Taylor, S.S. (2016) Decoding the Interactions Regulating the Active State Mechanics of Eukaryotic Protein Kinases. PLoS Biol. 14, e2000127. https://doi.org/10.1371/journal.pbio.2000127

90. Slice, L.W. and Taylor, S.S. (1989) Expression of the catalytic subunit of cAMP-dependent protein kinase in Escherichia coli. J Biol Chem. 264, 20940-6.

91. Batkin, M., Schvartz, I. and Shaltiel, S. (2000) Snapping of the carboxyl terminal tail of the catalytic subunit of PKA onto its core: characterization of the sites by mutagenesis. Biochemistry. 39, 5366 73. https://doi.org/10.1021/bi000153z

92. Yang, J., Kennedy, E.J., Wu, J., Deal, M.S., Pennypacker, J., Ghosh, G. and Taylor, S.S. (2009) Contribution of non-catalytic core residues to activity and regulation in protein kinase A. J Biol Chem. 284, 6241-8. https://doi.org/10.1074/jbc.M805862200

93. Kannan, N., Haste, N., Taylor, S.S. and Neuwald, A.F. (2007) The hallmark of AGC kinase functional divergence is its C-terminal tail, a cis-acting regulatory module. Proc Natl Acad Sci US A. 104, 12727. https://doi.org/10.1073/pnas.0610251104

94. Moore, M.J., Kanter, J.R., Jones, K.C. and Taylor, S.S. (2002) Phosphorylation of the catalytic subunit of protein kinase A. Autophosphorylation versus phosphorylation by phosphoinositide-dependent kinase-1. J Biol Chem. 277, 47878-84. https://doi.org/10.1074/jbc.M204970200

95. Keshwani, M.M., Klammt, C., von Daake, S., Ma, Y., Kornev, A.P., Choe, S., Insel, P.A. and Taylor, S.S. (2012) Cotranslational cisphosphorylation of the COOH-terminal tail is a key priming step in the maturation of cAMP-dependent protein kinase. Proc Natl Acad Sci US A. 109, E1221-9. https://doi.org/10.1073/pnas.1202741109

96. Herberg, F.W. and Taylor, S.S. (1993) Physiological inhibitors of the catalytic subunit of cAMP-dependent protein kinase: effect of MgATP on protein-protein interactions. Biochemistry. 32, 14015-22. https://doi.org/10.1021/bi00213a035

97. Zimmermann, B., Schweinsberg, S., Drewianka, S. and Herberg, F.W. (2008) Effect of metal ions on high-affinity binding of pseudosubstrate inhibitors to PKA. Biochem J. 413, 93-101. https://doi.org/10.1042/BJ20071665

98. Titani, K., Sasagawa, T., Ericsson, L.H., Kumar, S., Smith, S.B., Krebs, E.G. and Walsh, K.A. (1984) Amino acid sequence of the regulatory subunit of bovine type I adenosine cyclic 3',5'-phosphate dependent protein kinase. Biochemistry. 23, 4193-9. https://doi.org/10.1021/bi00313a028

99. Takio, K., Smith, S.B., Krebs, E.G., Walsh, K.A. and Titani, K. (1984) Amino acid sequence of the regulatory subunit of bovine type II adenosine cyclic 3',5'-phosphate dependent protein kinase. Biochemistry. 23, 4200-6. https://doi.org/10.1021/bi00313a029 
100. Weber, I.T., Takio, K., Titani, K. and Steitz, T.A. (1982) The cAMPbinding domains of the regulatory subunit of cAMP-dependent protein kinase and the catabolite gene activator protein are homologous. Proc Natl Acad Sci US A. 79, 7679-83.

https://doi.org/10.1073/pnas.79.24.7679

101. Kerlavage, A.R. and Taylor, S.S. (1980) Covalent modification of an adenosine 3':5'-monophosphate binding site of the regulatory subunit of cAMP-dependent protein kinase II with 8-azidoadenosine 3':5'-monophosphate. Identification of a single modified tyrosine residue. J Biol Chem. 255, 8483-8.

102. Bubis, J. and Taylor, S.S. (1985) Covalent modification of both cAMP binding sites in cAMP-dependent protein kinase I by 8 -azidoadenosine 3',5'-monophosphate. Biochemistry. 24, 2163-70. https://doi.org/10.1021/bi00330a009

103. Su, Y., Dostmann, W.R., Herberg, F.W., Durick, K., Xuong, N.H., Ten Eyck, L., Taylor, S.S. and Varughese, K.I. (1995) Regulatory subunit of protein kinase A: structure of deletion mutant with cAMP binding domains. Science. 269, 807-13. https://doi.org/10.1126/science.7638597

104. Diller, T.C., Xuong, N.H. and Taylor, S.S. (2000) Type II beta regulatory subunit of cAMP-dependent protein kinase: purification strategies to optimize crystallization. Protein Expr Purif. 20, 357-64. https://doi.org/10.1006/prep.2000.1312

105. Berman, H.M., Ten Eyck, L.F., Goodsell, D.S., Haste, N.M., Kornev, A. and Taylor, S.S. (2005) The cAMP binding domain: An ancient signaling module. Proceedings of the National Academy of Sciences of the United States of America. 102, 45-50. https://doi.org/10.1073/pnas.0408579102

106. Kornev, A.P., Taylor, S.S. and Ten Eyck, L.F. (2008) A generalized allosteric mechanism for cis-regulated cyclic nucleotide binding domains. PLoS Comput Biol. 4, e1000056. https://doi.org/10.1371/journal.pcbi.1000056

107. Murphy, C.S. and Steinberg, R.A. (1985) Hotspots for spontaneous and mutagen-induced lesions in regulatory subunit of cyclic AMPdependent protein kinase in $\mathrm{S} 49$ mouse lymphoma cells. Somat Cell Mol Genet. 11, 605-15. https://doi.org/10.1007/BF01534725

108. Steinberg, R.A., Russell, J.L., Murphy, C.S. and Yphantis, D.A. (1987) Activation of type I cyclic AMP-dependent protein kinases with defective cyclic AMP-binding sites. J Biol Chem. 262, 2664-71.

109. Kim, C., Xuong, N.H. and Taylor, S.S. (2005) Crystal structure of a complex between the catalytic and regulatory (RIalpha) subunits of PKA. Science. 307, 690-6. https://doi.org/10.1126/science.1104607

110. Kim, C., Cheng, C.Y., Saldanha, S.A. and Taylor, S.S. (2007) PKAI holoenzyme structure reveals a mechanism for cAMP-dependent activation. Cell. 130, 1032-43. https://doi.org/10.1016/j.cell.2007.07.018

111. Wu, J., Brown, S.H., von Daake, S. and Taylor, S.S. (2007) PKA type IIalpha holoenzyme reveals a combinatorial strategy for isoform diversity. Science. 318, 274-9. https://doi.org/10.1126/science.1146447

112. Boettcher, A.J., Wu, J., Kim, C., Yang, J., Bruystens, J., Cheung, N., Pennypacker, J.K., Blumenthal, D.A., Kornev, A.P. and Taylor, S.S. (2011) Realizing the Allosteric Potential of the Tetrameric Protein Kinase A RIalpha Holoenzyme. Structure. 19, 265-76. https://doi.org/10.1016/j.str.2010.12.005

113. Zhang, P., Smith-Nguyen, E.V., Keshwani, M.M., Deal, M.S., Kornev, A.P. and Taylor, S.S. (2012) Structure and Allostery of the PKA RIIbeta Tetrameric Holoenzyme. Science. 335, 712-6. https://doi.org/10.1126/science.1213979

114. Ilouz, R., Bubis, J., Wu, J., Yim, Y.Y., Deal, M.S., Kornev, A.P., Ma, Y., Blumenthal, D.K. and Taylor, S.S. (2012) Localization and quaternary structure of the PKA RIbeta holoenzyme. Proc Natl Acad Sci US A. 109, 12443-8. https://doi.org/10.1073/pnas.1209538109

115. Vigil, D., Blumenthal, D.K., Heller, W.T., Brown, S., Canaves, J.M., Taylor, S.S. and Trewhella, J. (2004) Conformational differences among solution structures of the type Ialpha, IIalpha and IIbeta protein kinase A regulatory subunit homodimers: role of the linker regions. J Mol Biol. 337, 1183-94.

https://doi.org/10.1016/j.jmb.2004.02.028
116. Vigil, D., Blumenthal, D.K., Taylor, S.S. and Trewhella, J. (2006) Solution scattering reveals large differences in the global structures of type II protein kinase A isoforms. J Mol Biol. 357, 880-9. https://doi.org/10.1016/j.jmb.2006.01.006

117. Taylor, S.S., Ilouz, R., Zhang, P. and Kornev, A.P. (2012) Assembly of allosteric macromolecular switches: lessons from PKA. Nature Reviews Molecular Cell Biology. 13, 646-658.

https://doi.org/10.1038/nrm3432

118. Burns, L.L., Canaves, J.M., Pennypacker, J.K., Blumenthal, D.K. and Taylor, S.S. (2003) Isoform specific differences in binding of a dual-specificity A-kinase anchoring protein to type I and type II regulatory subunits of PKA. Biochemistry. 42, 5754-63. https://doi.org/10.1021/bi0265729

119. Gold, M.G., Lygren, B., Dokurno, P., Hoshi, N., McConnachie, G., Tasken, K., Carlson, C.R., Scott, J.D. and Barford, D. (2006) Molecular basis of AKAP specificity for PKA regulatory subunits. Mol Cell. 24, 383-95. https://doi.org/10.1016/j.molcel.2006.09.006

120. Kinderman, F.S., Kim, C., von Daake, S., Ma, Y., Pham, B.Q., Spraggon, G., Xuong, N.H., Jennings, P.A. and Taylor, S.S. (2006) A dynamic mechanism for AKAP binding to RII isoforms of cAMPdependent protein kinase. Mol Cell. 24, 397-408. https://doi.org/10.1016/j.molcel.2006.09.015

121. Huang, L.J., Durick, K., Weiner, J.A., Chun, J. and Taylor, S.S. (1997) Identification of a novel protein kinase A anchoring protein that binds both type I and type II regulatory subunits.J Biol Chem. 272, 8057-64. https://doi.org/10.1074/jbc.272.12.8057

122. Huang, L.J., Durick, K., Weiner, J.A., Chun, J. and Taylor, S.S. (1997) D-AKAP2, a novel protein kinase A anchoring protein with a putative RGS domain. Proc Natl Acad Sci U S A. 94, 11184-9. https://doi.org/10.1073/pnas.94.21.11184

123. Burgers, P.P., Ma, Y., Margarucci, L., Mackey, M., van der Heyden, M.A., Ellisman, M., Scholten, A., Taylor, S.S. and Heck, A.J. (2012) A small novel A-kinase anchoring protein (AKAP) that localizes specifically protein kinase A-regulatory subunit I (PKA-RI) to the plasma membrane. J Biol Chem. 287, 43789-97. https://doi.org/10.1074/jbc.M112.395970

124. Bachmann, V.A., Mayrhofer, J.E., Ilouz, R., Tschaikner, P., Raffeiner, P., Rock, R., Courcelles, M., Apelt, F., Lu, T.W., Baillie, G.S., Thibault, P., Aanstad, P., Stelzl, U., Taylor, S.S. and Stefan, E. (2016) Gpr161 anchoring of PKA consolidates GPCR and cAMP signaling. Proc Natl Acad Sci US A. 113, 7786-91. https://doi.org/10.1073/pnas.1608061113

125. Eggers, C.T., Schafer, J.C., Goldenring, J.R. and Taylor, S.S. (2009) D-AKAP2 interacts with Rab4 and Rab11 through its RGS domains and regulates transferrin receptor recycling. J Biol Chem. 284, 32869-80. https://doi.org/10.1074/jbc.M109.022582

126. Sarma, G.N., Kinderman, F.S., Kim, C., von Daake, S., Chen, L., Wang, B.C. and Taylor, S.S. (2010) Structure of D-AKAP2:PKA RI complex: insights into AKAP specificity and selectivity. Structure. 18, 155-66. https://doi.org/10.1016/j.str.2009.12.012

127. Sarma, G.N., Moody, I.S., Ilouz, R., Phan, R.H., Sankaran, B., Hall, R.A. and Taylor, S.S. (2014) D-AKAP2:PKA RII:PDZK1 ternary complex structure: Insights from the nucleation of a polyvalent scaffold. Protein Sci.

128. Romano, R.A., Kannan, N., Kornev, A.P., Allison, C.J. and Taylor, S.S. (2009) A chimeric mechanism for polyvalent trans-phosphorylation of PKA by PDK1. Protein Sci. 18, 1486-97. https://doi.org/10.1002/pro.146

129. Herberg, F.W., Zimmermann, B., McGlone, M. and Taylor, S.S. (1997) Importance of the A-helix of the catalytic subunit of cAMPdependent protein kinase for stability and for orienting subdomains at the cleft interface. Protein Science. 6, 569-579. https://doi.org/10.1002/pro.5560060306

130. Bastidas, A.C., Deal, M.S., Steichen, J.M., Keshwani, M.M., Guo, Y. and Taylor, S.S. (2012) Role of N-Terminal Myristylation in the Structure and Regulation of cAMP-Dependent Protein Kinase. $J$ Mol Biol. 422, 215-29. https://doi.org/10.1016/j.jmb.2012.05.021 